\title{
Epidemiology of, and risk factors for, Helicobacter pylori infection among 3194 asymptomatic subjects in 17 populations
}

\author{
The EUROGAST Study Group
}

\begin{abstract}
The cross sectional study describes the prevalence of infection with Helicobacter pylori as determined by a serodiagnostic assay in over 3000 asymptomatic subjects, in two age groups 25-34 years and 55-64 years, from 17 geographically defined populations in Europe, North Africa, North America, and Japan, using a common protocol for blood collection and serological testing. In all populations combined, the prevalence of infection was higher in the older age group $(62.4 \%)$ than in the younger age group (34.9\%). There was no difference in prevalence of infection between men and women. Subjects with higher education had considerably lower levels of infection (34.1\%) compared with subjects with education up to secondary level $(46.9 \%)$ or those with primary education only (61.6\%). This trend was confined to the older of the two age groups. In contrast a trend of increasing prevalence of infection with increasing body mass index was confined to the younger of the two age groups. There was no effect of smoking or alcohol consumption on the prevalence of infection after adjusting for the other risk factors. There was considerable variation in the prevalence of infection between the 17 populations but, within populations, low education standard was consistently and positively associated with the prevalence of infection.

(Gut 1993; 34: 1672-1676)
\end{abstract}

Helicobacter pylori ( $H$ pylori) is a spiral shaped microaerophilic bacterium that colonises the gastric mucosa and causes both acute ${ }^{1}$ and chronic $^{2}$ gastritis. This has initiated new, active lines of investigation into the clinical and aetiological aspects of gastric disease. It is now established that $H$ pylori infection is a persistent condition that is probably related to the occurrence and relapse of peptic ulcer disease, ${ }^{3}$ and, possibly, to the risk of gastric cancer. ${ }^{46}$

Infection with $H$ pylori may be detected by histological examination of the gastric mucosa or by culture of endoscopic biopsy specimens, or by less invasive techniques such as the urea breath test or serological tests to detect the presence of circulating, specific IgG antibodies. Serodiagnostic tests are most frequently used for epidemiological studies and have been used to measure the prevalence of infection in various populations. ${ }^{78}$ Few of these studies, however, have been conducted in unselected, random samples of the general population and differences in the sources and handling of samples, as well as differences between assays, make comparisons between the studies difficult.

The EUROGAST study was undertaken to investigate the epidemiology of $H$ pylori infection and chronic gastritis, and to relate these biological entities to the occurrence of gastric cancer in different asymptomatic populations. A common protocol for blood collection and questionnaires was developed and applied to more than 3000 subjects from 17 populations from 13 countries. This paper presents data on the variability of prevalence of $H$ pylor infection and attempts to identify factors associated with infection. A previous publication has reported on the positive association between $H$ pylori infection and gastric cancer risk.' Unique features of this investigation were the very large sample size, representative sampling of study participants from geographically well defined populations, the diversity of the component study populations, the use of a standard protocol for identification and invitation of participants, questionnaires and blood collection, and the processing of serum samples in a single laboratory.

\section{Materials and methods}

The methodology for the EUROGAST study is described in detail elsewhere (EUROGAST study group, manuscript in preparation). Briefly, 17 populations throughout the world were chosen to reflect, as far as possible, the global range of gastric cancer incidence and mortality. The populations initially selected for the study were representative of the range of gastric cancer incidence in Europe and this range was subsequently extended by the addition of populations from the United States and Japan. In 13 of the 17 study centres (listed in Table I), about 200 subjects were selected at random from population based registers and invited, by letter or telephone, or both to participate in the study. In the two United Kingdom centres, Oxford and Stoke, subjects were selected randomly from the list of a family doctor group practice, in the US centre, Minneapolis-St Paul, subjects were selected from driving licence rosters and in the Greek centre, Crete, subjects were selected partly $(64 \%)$ from residence lists in two villages and partly (36\%) from attendees at a trade union health screening programme.

The study aimed at recruiting $\mathbf{5 0}$ men and $\mathbf{5 0}$ women in each of the two age groups, 25-34 years and 55-64 years. Non-respondents were followed up with further letters, telephone calls, and home visits. Subjects who could not be contacted or who refused to participate were, in
Dr D Forman, Imperia Cancer Research Fund, Cancer Epidemiology Unit, Gibson Building, Radcliffe Accepted for publication 29 April 1993 
TABLE I EUROGAST Study Centres

\begin{tabular}{lll}
\hline Country & Centre & Sample size \\
\hline Algeria & Algiers (AL) & 200 \\
Belgium & Ghent (GH) & 208 \\
Denmark & Copenhagen (CO) & 157 \\
Germany & Augsburg (AU) & 187 \\
& Deggendorf(DE) & 198 \\
& Mosbach (MO) & 158 \\
Greece & Crete (CR) & 229 \\
Iceland & S Region(IC) & 206 \\
Italy & Florence (FL) & 205 \\
Japan & Miyagi (MY) & 186 \\
Poland & Yokote (YO) & 200 \\
Portugal & Adamowka (AD) & 171 \\
Slovenia & Gaia (GA) & 132 \\
UK & Ljubljana (LJ) & 201 \\
& Oxford (OX) & 158 \\
US & Stoke (ST) & 200 \\
& Minneapolis St Paul (MS) & 198 \\
\hline
\end{tabular}

general, replaced by additional subjects in the same age and sex group. Participating subjects provided a blood sample and answered a short questionnaire concerning sociodemographic details.

Serum was collected, stored, and transported according to an identical protocol in each centre. Analysis for anti- $H$ pylori IgG antibodies was carried out with an enzyme linked immunoassay (ELISA), ${ }^{10}$ slightly modified, ${ }^{11}$ using duplicate determinations. A threshold of $10 \mu \mathrm{g}$ specific IgG per $\mathrm{ml}$ was used to discriminate $H$ pylori positive from $H$ pylori negative subjects. To test assay repeatability, about one in $\mathbf{4 0}$ samples were analysed a second time with the laboratory blind to the initial assay results. Selection for repeat assays was weighted to have an over-representation of samples close to the $10 \mu \mathrm{g}$ per $\mathrm{ml}$ threshold. The external sensitivity and specificity of this test were $96 \%$ and $93 \%$, respectively as determined in a trial with serum samples from the USA, against a gold standard of histology and microbiological culture."

The seroprevalence of $H$ pylori infection was analysed in relation to sex, age, standard of education (the highest standard of school education obtained, coded as primary, secondary or higher education), tobacco smoking, alcohol drinking (in the week before the interview), history of gastric operation (self reported), and height and weight. Odds ratio (OR) of $H$ pylori

Figure 1: Frequency distribution of serum anti$\mathrm{H}$ pylori $\operatorname{Ig} G$ concentrations.

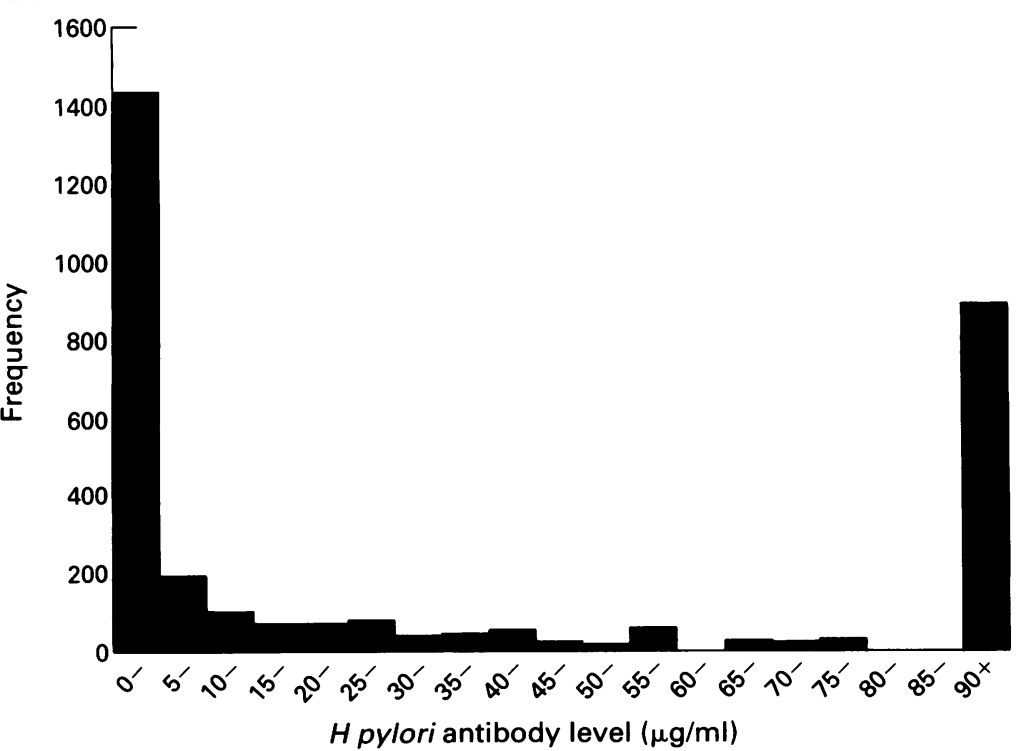

infection given the presence of a particular characteristic were used as the measure of association, and these are presented together with $95 \%$ confidence intervals $(\mathrm{CI})$. Effects were considered to be statistically significant if the $95 \%$ CI did not include the value $1 \cdot 0$, corresponding with a two sided $p$ value of 0.05 or less. Adjusted ORs were estimated by multivariate unconditional logistic regression analysis. ${ }^{12}$

\section{Results}

In total, serum samples from 3194 subjects were assayed for the presence of anti- $H$ pylori IgG antibodies. Figure 1 shows the frequency distribution of the antibody levels, which is clearly bimodal. Overall 1563 (48.9\%) samples were seropositive with $\geqslant 10 \mu \mathrm{g}$ specific IgG per $\mathrm{ml}$. Nine hundred and one samples $(28.2 \%)$ had an antibody level of $>90 \mu \mathrm{g}$ specific IgG per $\mathrm{ml}$, the maximum detectable for the assay under these conditions, while 1436 samples $(45 \cdot 0 \%)$ had a level of less than $5 \mu \mathrm{g}$ per $\mathrm{ml}$. Three hundred samples $(9 \cdot 4 \%)$ had levels between 5 and $15 \mu \mathrm{g}$ specific IgG per $\mathrm{ml}$, - that is, close to the cut off point. The repeat assay on one in 40 samples produced qualitatively identical results in 29 of 34 samples (85\%) with an initial specific IgG concentration of less than $5 \mu \mathrm{g}$ per $\mathrm{ml}$, in seven of 15 samples (47\%) with 5-15 $\mu$ g IgG per ml and in all 27 samples (100\%) with $16 \mu$ g IgG per $\mathrm{ml}$ or greater.

Figure 2 shows the $H$ pylori seropositivity in each population. Among the 25-34 year age group, the seropositivity ranged from $15 \%$ or less in Oxford, Minneapolis-St Paul, and Copenhagen to more than $50 \%$ in Gaia, Adamowka, Crete, Miyagi, and Yokote. In all populations, the seropositivity was higher among the 55-64 age group than among those aged 25-34. In subjects aged 55-64, the seropositivity ranged from around $30 \%$ in Copenhagen and Minneapolis-St Paul to more than $80 \%$ in Adamowka, Miyagi, and Yokote. The difference in prevalence of seropositivity between the two age groups varied from about $15 \%$ in Gaia, Algiers, Adamowka, and Copenhagen, to more than $35 \%$ in Oxford, Ghent, and the three German populations.

Table II shows how taking all populations together, the seropositivity for $H$ pylori varied with other characteristics of the subjects. Age had a profound effect on the probability of being seropositive but there was no difference between men and women. $H$ pylori seropositivity showed a significant inverse trend $(p<0.0001)$ with standard of education, from $34 \%$ in subjects with a higher education to $47 \%$ in subjects with secondary education to $62 \%$ in subjects with only primary school education. After mutual adjustment, and adjustment for centre, using multivariate analysis, the effect of standard of education on seropositivity was attenuated, pointing to some degree of confounding, but remained statistically highly significant $(\mathrm{p}<0.001)$.

In univariate analysis, tobacco smoking and alcohol drinking were associated with a reduced prevalence of $H$ pylori seropositivity, but these effects disappeared completely after adjustment 
Figure 2: Prevalence of $\mathrm{H}$ pylori infection, defined as specific IgG antibodies $\geqslant 10 \mu \mathrm{g} / \mathrm{ml}$, in two age groups in 17 geographical populations. See Table I for $a$ list of the abbreviated names of populations. Each line contains data for a single population with results of men and women combined. The separation into two graphs is solely for legibility.

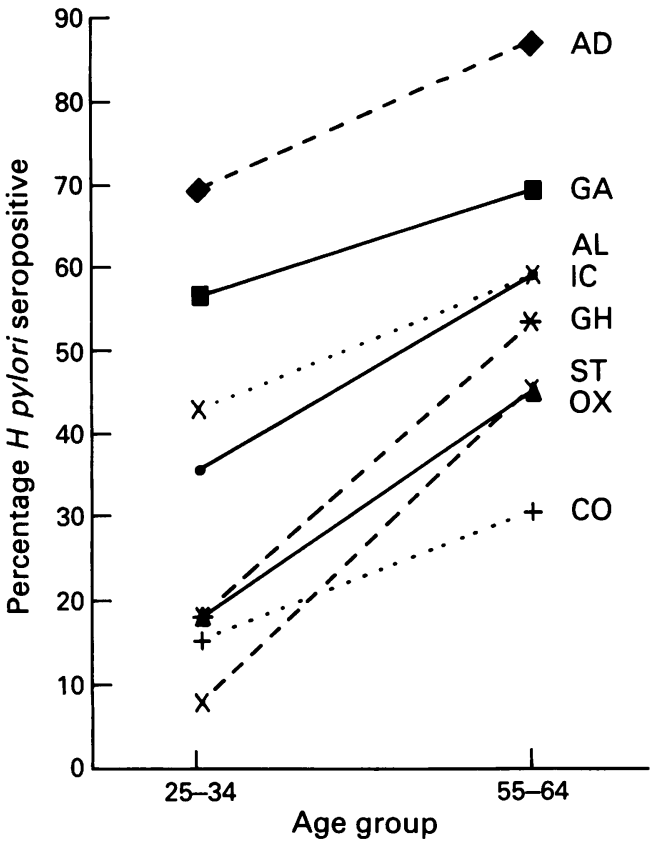

in the multivariate analysis. The 62 subjects who reported having had a gastric operation had an increased $H$ pylori seropositivity but this effect was not significant in the multivariate analysis.

There were significant trends in $H$ pylori seropositivity with both height and weight in univariate analysis: being taller than average (within local populations) was indicative of low seropositivity while being heavier than average was indicative of higher $H$ pylori seropositivity. Both of these trends were non-significant after adjustment. Body mass index (BMI=weight $(\mathrm{kg}) /$ height $\left.\left(\mathrm{m}^{2}\right)\right)$ is a measure of weight, adjusted for height. The trend of $H$ pylori seropositivity with BMI .was statistically significant in univariate analysis $(p<0.0001)$ and of borderline

TABLE II Prevalence of $\mathrm{H}$ pylori seropositivity by categories of independent variables: univariate and adjusted odds ratios (OR)

\begin{tabular}{|c|c|c|c|}
\hline $\begin{array}{l}\text { Variable and } \\
\text { categories }\end{array}$ & $\begin{array}{l}\text { Prevalence } \\
\%(n)\end{array}$ & $\begin{array}{l}\text { Univariate } \\
\text { OR }(95 \% C I)\end{array}$ & $\begin{array}{l}\text { Adjusted } \\
\text { OR }(95 \% C I)\end{array}$ \\
\hline \multicolumn{4}{|l|}{ Sex: } \\
\hline Male & $49 \cdot 1(1575)$ & $1 \cdot 0$ & \\
\hline \multicolumn{4}{|l|}{ Age: } \\
\hline $\begin{array}{l}25-34 \\
55-64\end{array}$ & $\begin{array}{l}34.9(1558) \\
62 \cdot 4(1636)\end{array}$ & $\begin{array}{l}1 \cdot 0 \\
3 \cdot 1(2 \cdot 7 \text { to } 3 \cdot 6)\end{array}$ & $\begin{array}{l}1 \cdot 0 \\
3 \cdot 0(2 \cdot 5 \text { to } 3.6)\end{array}$ \\
\hline \multicolumn{4}{|c|}{ Education standard: } \\
\hline $\begin{array}{l}\text { Primary } \\
\text { Secondary } \\
\text { Higher }\end{array}$ & $\begin{array}{l}61 \cdot 6(1054) \\
46 \cdot 9(1426) \\
34 \cdot 1(700)\end{array}$ & $\begin{array}{l}1.0 \dagger \\
0.6(0.5 \text { to } 0.6) \\
0.3(0.3 \text { to } 0.4)\end{array}$ & $\begin{array}{l}1.0 \dagger \\
0.8(0.6 \text { to } 1.0) \\
0.6(0.4 \text { to } 0.8)\end{array}$ \\
\hline \multicolumn{4}{|l|}{ Smokin } \\
\hline Never & $50.9(1598)$ & $1 \cdot 0$ & \\
\hline Former & 48 . & $1 \cdot 1)$ & $1 \cdot 2(0$. \\
\hline \multirow{2}{*}{\multicolumn{4}{|c|}{ Alcohol: }} \\
\hline & & & \\
\hline None & $55 \cdot 2(1271)$ & & \\
\hline Some & $44.5(1897)$ & $0.7(0$ & i. \\
\hline \multicolumn{4}{|c|}{ Gastric operation: } \\
\hline No & $48 \cdot 4(3024)$ & $1 \cdot 0$ & $1 \cdot($ \\
\hline \multicolumn{4}{|c|}{ Tertile of height (by sex and within centre): } \\
\hline Low & $56 \cdot 0(1043)$ & $1.0 \dagger$ & \\
\hline Middle & $49 \cdot 3(1074)$ & $0.8(0.6$ to 0.9$)$ & \\
\hline High & $41 \cdot 5(1063)$ & $0.6(0.5$ to 0.7$)$ & \\
\hline \multicolumn{4}{|c|}{ Tertile of weight (by sex and within centre): } \\
\hline Low & $46 \cdot 4(1046)$ & $1.0+$ & \\
\hline Middle & $47 \cdot 7(1078)$ & $1 \cdot 1(0.9$ to $1 \cdot 3)$ & \\
\hline High & $52 \cdot 6(1048)$ & $1 \cdot 3(1 \cdot 1$ to $1 \cdot 5)$ & \\
\hline \multicolumn{4}{|c|}{ Tertile of BMI (by sex and within centre) } \\
\hline Low & $41 \cdot 1(1045)$ & $1.0+$ & $1 \cdot 0$ \\
\hline Middle & $49 \cdot 1(1070)$ & $1.4(1$ & $1 \cdot 2(0$. \\
\hline High & $56.4(1057)$ & $1.9(1.6$ to 2.2$)$ & $1.2(1.0$ to 1 . \\
\hline
\end{tabular}

$\star$ Mutually adjusted and adjusted for centre.

$t \chi^{2}$ test for trend: $p<0.05 ; B M I=$ body mass index

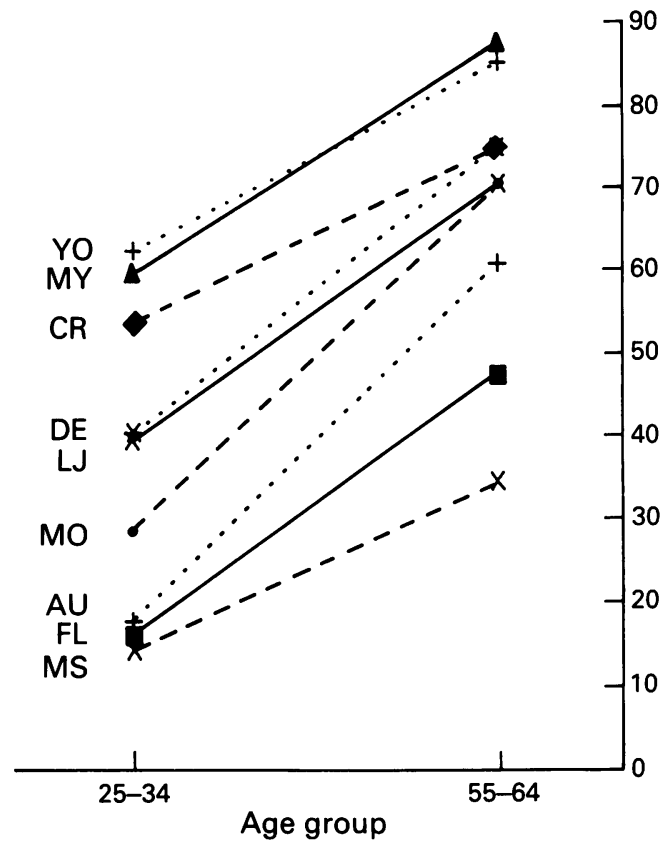

significance after multivariate analysis $(\mathrm{p}=0.079)$.

Table III shows the results of the multivariate analysis separately for men and women, and separately for the two age groups. The effects of age, education standard, and BMI on $H$ pylori seropositivity were similar in men and women. Consideration of the two age groups separately, however, showed that the effect of education standard was largely confined to the older age group, while the effect of BMI was seen only in the younger age group.

Table IV shows the results of the multivariate analysis separately for each study population. This Table should be interpreted with caution because of the limited number of subjects in each centre. The effect of age was consistent across centres, although not statistically significant in three centres after adjusting for other factors. The effect of a high standard of education was seen in 11 of 17 centres (six significant individually), while in Deggendorf, Gaia, Crete and the two Japanese centres, the effect was in the opposite direction but not significant. The positive association between BMI and seropositivity was less consistent than the effect of the standard of education, and was absent or reversed in some populations.

\section{Discussion}

The cut off point for $H$ pylori seropositivity at 10 $\mu \mathrm{g}$ specific IgG per $\mathrm{ml}^{11}$ was selected to optimise the sensitivity and specificity of the assay against histological and microbiological diagnosis. As a consequence of the clear bimodal distribution of antibody concentration (Fig 1), the use of lower or higher cut off points did not materially influence the study results. As anticipated, assay repeatability was poor close to the cut off (5-15 $\mu \mathrm{g}$ per $\mathrm{ml}$ ), affecting a minority of samples, but was extremely good at lower or higher values.

The variation in the prevalence of $H$ pylori positivity between the populations chosen for this study is more than eightfold in the 25-34 year age group and nearly threefold in the 55-64 
TABLE III Adjusted odds ratios for $\mathrm{H}$ pylori seropositivity for various risk factors, by sex and age

\begin{tabular}{|c|c|c|c|c|}
\hline \multirow{2}{*}{$\begin{array}{l}\text { Variable and } \\
\text { categories }\end{array}$} & \multicolumn{2}{|l|}{ Sex } & \multicolumn{2}{|l|}{ Age (y) } \\
\hline & Male & Female & $25-34$ & $55-64$ \\
\hline \multicolumn{5}{|l|}{ Age: } \\
\hline $\begin{array}{l}25-34 \\
55-64\end{array}$ & $\begin{array}{l}1 \cdot 0 \\
2 \cdot 9 \star\end{array}$ & $\begin{array}{l}1 \cdot 0 \\
3 \cdot 1 \star\end{array}$ & & \\
\hline \multicolumn{5}{|c|}{ Education standard: } \\
\hline $\begin{array}{l}\text { Primary } \\
\text { Secondary }\end{array}$ & $\begin{array}{l}1.0 \dagger \\
0.9\end{array}$ & $\begin{array}{l}1 \cdot 0 \dagger \\
0.7^{\star}\end{array}$ & $\begin{array}{l}1.0 \\
0.9\end{array}$ & $\begin{array}{l}1 \cdot 0 \dagger \\
0 \cdot 6^{\star}\end{array}$ \\
\hline Higher & $0 \cdot 7^{\star}$ & $0.5^{\star}$ & 0.9 & $0 \cdot 3^{\star}$ \\
\hline \multicolumn{5}{|l|}{ Smoking: } \\
\hline Never & $1 \cdot 0$ & $1 \cdot 0$ & $1 \cdot 0$ & $1 \cdot 0$ \\
\hline Former & $1 \cdot 1$ & $1 \cdot 2$ & $1 \cdot 3$ & $1 \cdot 2$ \\
\hline Current & 0.9 & $1 \cdot 0$ & 0.9 & $1 \cdot 2$ \\
\hline \multicolumn{5}{|l|}{ Alcohol: } \\
\hline None & $1 \cdot 0$ & $1 \cdot 0$ & $1 \cdot 0$ & $1 \cdot 0$ \\
\hline Some & 0.8 & $1 \cdot 0$ & 0.9 & $1 \cdot 0$ \\
\hline \multicolumn{5}{|c|}{ Gastric operation: } \\
\hline No & $1 \cdot 0$ & $1 \cdot 0$ & $1 \cdot 0$ & $1 \cdot 0$ \\
\hline $\begin{array}{l}\text { Yes } \\
\text { Tertile of BM }\end{array}$ & $2 \cdot 1^{\star}$ & $1 \cdot 1$ & $1 \cdot 5$ & $1 \cdot 5$ \\
\hline \multicolumn{5}{|c|}{ Tertile of BMI (by sex and within centre): } \\
\hline Low & 1.0 & $1 \cdot 0$ & $1 \cdot 0+$ & $1 \cdot 0$ \\
\hline Middle & $1 \cdot 0$ & $1 \cdot 3$ & $1 \cdot 3$ & $1 \cdot 0$ \\
\hline High & $1 \cdot 2$ & $1 \cdot 2$ & $1 \cdot 4$ & $1 \cdot 0$ \\
\hline
\end{tabular}

$\star=\mathrm{p}<0.05 ; \dagger=\chi^{2}$ test for trend: $\mathrm{p}<0.05 ; \mathrm{BMI}=$ body mass index

year age group. The increasing prevalence with age is a well known feature of the epidemiology of $H$ pylori infection. ${ }^{7813}$ Very little is known about the sources of $H$ pylori or of the routes of transmission between subjects. The very high prevalence of infection reported among children in certain populations from developing countries $^{71314}$ and the high prevalence in occupationally exposed gastroenterologists ${ }^{15}$ show that people may be susceptible to infection in both childhood and adult life and will develop a chronic infection manifest by a circulating specific IgG antibody response.

The large difference in prevalence between the two age groups may be caused by two different mechanisms: an age effect or a cohort effect. The older subjects in the study could have a higher prevalence of infection either because they have lived longer and hence have had more opportunity for infection, or because they were born at a time when the risk of infection in childhood was higher than in those born later. The present data can neither distinguish between these possibilities nor estimate the comparative contribution of each effect in the populations studied.

The low slope of the age prevalence relation in some high prevalence populations (Gaia, Algiers, and Adamowka) may indicate that saturation occurs at prevalence values below $100 \%$, or, alternatively, that the risk factors in these populations have been highly prevalent in the life span of both the 25-34 age group and the 55-64 age group. Populations with a steep slope and intermediate prevalence (for example, the two UK populations and the three German populations) may show that the infection in these populations is most often acquired in middle age, or, alternatively, that some aspect of living conditions has improved considerably in the younger part of these populations compared with the older. Finally, populations with a comparatively low slope and low value of prevalence (Copenhagen and Minneapolis-St Paul) may point to a situation in which a low level of exposure to risk factors (or a high level of exposure to protective factors) occurred during the life span both of the younger and the older parts of the populations. The slope of the line for the latter two populations corresponds well with the seroconversion rate of $0.5 \%$ per year in a cohort of predominantly white American epidemiologists. ${ }^{16}$

The risk factors for $H$ pylori infection, other than age, which emerge from the present study low standard of education and, to a lesser extent, high BMI - should probably not be interpreted as direct causal factors, indicative of the actual routes of infection. Rather, these factors may be indirect markers of the mechanisms of transmission of infection.

Standard of education is obviously a strong indicator of socioeconomic class, especially in the older subjects who grew up in a period when the possibility of a secondary or higher education was restricted to the upper strata of society in many of the study populations.

No previous study has shown an association between $H$ pylori infection and BMI. In contrast with the effect of education standard, the effect of BMI was most pronounced in the younger age group. Possibly BMI at a young age reflects more accurately the relevant social class related aspects of current living conditions than does BMI at older age. Alternatively, BMI at older age may be more dominated by random variation, which would tend to reduce the magnitude of an effect. BMI is essentially a measure of weight adjusted for height. It is usually thought that adult height is more strongly associated with childhood socioeconomic conditions than is adult weight. Consequently one might have expected, a priori, $H$ pylori infection to be more strongly associated with height than with weight or BMI. Although height was related to seroprevalence in the univariate analysis (Table II), when it was entered into the multivariate model, with or without weight, the relation was no longer found.

Many other studies have identified social class as an important determinant of $H$ pylori infection. ${ }^{81718}$ Moreover, recent studies have also reported a strong association between $H$ pylori

TABLE IV Adjusted ${ }^{\star}$ odds ratios for $\mathbf{H}$ pylori seropositivity for various risk factors, by centre (comparative with lowest categoryt)

\begin{tabular}{|c|c|c|c|c|c|c|c|c|c|c|c|c|c|c|c|c|c|}
\hline Centre & $A L$ & $G H$ & $\mathrm{CO}$ & $A U$ & $D E$ & $M O$ & $C R$ & $I C$ & $F L$ & $M Y$ & $Y O$ & $A D$ & $G A$ & $L \mathcal{F}$ & $O X$ & $S T$ & $M S$ \\
\hline $\begin{array}{l}\text { Age 55-64 } \\
\text { Education: }\end{array}$ & 1.6 & $3.8 \dagger$ & 1.7 & $4 \cdot 2 \dagger$ & $4 \cdot 2 \dagger$ & $4 \cdot 2 t$ & $3.4 \dagger$ & $2.6 \dagger$ & $3.6 t$ & $7 \cdot 0+$ & $4 \cdot 1 \dagger$ & $3.0+$ & 1.7 & $3.4 \dagger$ & $8 \cdot 1 \dagger$ & $3 \cdot 5 \dagger$ & $2 \cdot 0 \dagger$ \\
\hline Secondary & 0.8 & $0 \cdot 2 \dagger$ & 0.4 & $0.4 \dagger$ & $2 \cdot 5 t$ & 0.9 & $3 \cdot 2$ & $0 \cdot 8$ & 0.5 & & $1 \cdot 0$ & $1 \cdot 3$ & $1 \cdot 0$ & 0.6 & & & \\
\hline $\begin{array}{l}\text { Higner } \\
\text { Tertile of BMI (by }\end{array}$ & $\begin{array}{l}0.8 \\
\text { ex): }\end{array}$ & & & & & & & & $0.4 \delta$ & $1 \cdot 1$ & 1 & & 2 & & $0.2 \dagger$ & 0.6 & $0.5 \uparrow$ \\
\hline $\begin{array}{l}\text { Middle } \\
\text { High }\end{array}$ & $\begin{array}{l}1 \cdot 2 \\
1 \cdot 3\end{array}$ & $\begin{array}{l}1 \cdot 1 \\
1 \cdot 4\end{array}$ & $\begin{array}{l}1.9 \\
2.0\end{array}$ & $\begin{array}{l}1 \cdot 0 \\
2 \cdot 8+5\end{array}$ & $\begin{array}{l}1 \cdot 2 \\
2 \cdot 7+5\end{array}$ & $\begin{array}{l}1 \cdot 8 \\
2 \cdot 4\end{array}$ & $\begin{array}{l}4.4 \dagger \\
1.5\end{array}$ & $\begin{array}{l}0.6 \\
0.5\end{array}$ & $\begin{array}{l}1 \cdot 6 \\
1 \cdot 1\end{array}$ & $\begin{array}{l}0.8 \\
0.3+5\end{array}$ & $\begin{array}{l}1 \cdot 8 \\
1 \cdot 3\end{array}$ & $\begin{array}{l}1 \cdot 5 \\
1 \cdot 1\end{array}$ & $\begin{array}{l}1 \cdot 7 \\
0.7\end{array}$ & $\begin{array}{l}0.7 \\
0.9\end{array}$ & $\begin{array}{l}0.8 \\
0.6\end{array}$ & $\begin{array}{l}1.2 \\
0.8\end{array}$ & $\begin{array}{l}0.5 \\
1.6\end{array}$ \\
\hline
\end{tabular}

^Mutually adjusted and adjusted, where possible, for previous gastric operation, alcohol, and smoking; †except 'higher education' in Miyagi, Oxford, Stoke, and Minneapolis-St Paul comparative with 'secondary education'; $\ddagger=p<0.05 ; \S=p<0.05$, $\chi^{2}$ test for trend. 
infection in adults and living conditions, especially crowding, in childhood. ${ }^{19} 20$ The lack of an apparent effect of low standard of education in four study centres may be a result of chance, absence of variation in education standards, or a lack of an association between educational standard and socioeconomic conditions in these centres. The last explanation may be particularly relevant to the two Japanese centres.

A history of gastric operation was reported by $2 \%$ of the study subjects. The percentage ranged from $0 \%$ in Mosbach to $6 \%$ in Miyagi. Self reported gastric operation is not necessarily reliable, because other abdominal operations may be included. Most subjects, however, reported having been operated for peptic ulcer disease. Despite the low prevalence and the possible inaccuracy, the prevalence of $H$ pylori infection seems to be substantially increased in subjects who reported having had a stomach operation. This is consistent with the high prevalence of infection in patients with clinically diagnosed peptic ulcer disease. ${ }^{321}$

The risk of $H$ pylor infection seems to have no association with tobacco smoking or with alcohol drinking, findings consistent with other studies. ${ }^{22} 23$ The apparent protective effects disappeared completely after adjustment for other factors and are therefore most likely to be attributable to confounding.

In conclusion, this cross sectional study of $H$ pylori infection, based on particularly large numbers, establishes beyond reasonable doubt that factors related to social class are important determinants of the risk of infection within populations, in both sexes, while tobacco smoking and alcohol drinking are not associated with the prevalence of $H$ pylori infection. After accounting for the effects of age, educational standard, and body mass index most of the geographical variation in $H$ pylori seropositivity remains unexplained. Future work should attempt to elucidate the sources and routes of transmission of $H$ pylori infection.

1 Morris A, Nicholson G. Ingestion of Campylobacter pyloridis causes gastritis and raised fasting gastric $\mathrm{pH}$. $\mathrm{Am} \mathscr{J}$ Gastroenterol 1987; 82: 192-9.

2 Dixon MF. Helicobacter pylori and chronic gastritis. In Rathbone BJ, Heatly RV, eds. Helicobacter pylori and gastroduodenal disease. 2nd Ed. Oxford: Blackwel
Scientific, 1992: 124-39.

3 Moss S, Calam J. Helicobacter pylori and peptic ulcers: the present position. Gut 1992; 33: 289-92

4 Forman D, Newell DG, Fullerton F, Yarnell JWG, Stacey AR, Wald N, Sitas F. Association between infection with Helicobacter pylori and risk of gastric cancer: evidence from a prospective investigation. BMF 1991; 302: 1302-5.

5 Nomura A, Stemmermann GN, Chyou P-H, Kato I, PerezPerez GI, Blaser MJ. Helicobacter pylori infection and Pastric carcinoma among Japanese Americans in Hawaii. gastric carcinoma among Japanese

6 Parsonnet J, Friedman GD, Vandersteen DP, Chang Y, Vogelman $\mathrm{JH}$, Orentreich $\mathrm{N}$, et al. Helicobacter pylor infection and the risk of gastric carcinoma. $N$ Engl $\mathcal{F} M e d$ 1991; 325: 1127-31

7 Megraud F. Epidemiology of Helicobacter pylori infection In: Rathbone BJ, Heatley RV, eds. Helicobacter pylori and gastroduodenal disease. 2nd Ed. Oxford: Blackwell Scientific, 1992: 107-23.

8 Sitas F, Forman D, Yarnell JWG, Burr ML, Elwood PC Pedley $\mathrm{S}$, et al. Helicobacter pylori infection rates in relation to age and social class in a population of Welsh men. $G u t$ 1991; 32: 25-8.

9 The EUROGAST Study Group. An international association between Helicobacter pylori infection and gastric cancer: an international study. Lancet 1993; 341: 1359-62.

10 Steer HW, Hawtin PR, Newell DG. An ELISA technique for the serodiagnosis of Campylobacter pyloridis infection in the serodiagnosis of Campylobacter pyloridis infection in patients with gastritis and benign duoden

11 Talley NJ, Newell DG, Ormand JE, Carpenter HE, Wilson
WE, Zinsmeister AR, et al. Serodiagnosis of Helicobacter pylori: comparison of enzyme linked immunosorbent assays. 7 Clin Microbiol 1991; 29: 1635-9.

12 Breslow NE, Day NE. Statistical methods in cancer research. Vo 1. The analysis of case-control studies (IARC Scientific Publications No. 32). Lyon: IARC, 1980.

13 Taylor DN, Blaser MJ. The epidemiology of Helicobacter pylori infection. Epidemiol Rev 1991; 13:42-59.

14 Mitchell HM, Li YY, Hu PJ, Liu Q, Chen M, Du GG, et al. Epidemiology of Helicobacter pylori infection in Souther China: identification of early childhood as the critical period of acquisition. $\mathcal{F}$ Infect Dis 1992; 166: 149-53.

15 Mitchell HM, Lee A. Carrick J. Increased incidence of Campylobacter pylori infection in gastroenterologists: further evidence to support person-to-person transmission of C. pylori. Scand F Gastroenterol 1989; 24: 396-400.

16 Parsonnet J, Blaser MJ, Perez-Perez GI, Hargrett-Bean N, Tauxe RV. Symptoms and risk factors of Helicobacter pylori infection in a cohort of epidemiologists. Gastroenterolog infection in a coh $102: 41-6$.

17 Fiedorek SC, Malaty HM, Evans DL, Pumphrey LL, Lasteel $\mathrm{HB}$, Evans DJ, et al. Factors influencing the epidemiology of Helicobacter pylori in children. Pediatrics 1991; 88: 578-82.

18 Al-Moagel MA, Evans DG, Abdulghani ME, Adam E, Evan DJ Jr, Malaty HM, et al. Prevalence of Helicobacte (formerly Campylobacter) pylori infection in Saudi Arabia, and comparison of those with and without upper gastrointestinal symptoms. Am $\mathcal{F}$ Gastroenterol 1990; 85: 944-8.

19 Galpin OP, Whitaker CJ, Dubiel AJ. Helicobacter pylor infection and overcrowding in childhood. Lancet 1992; 339: 619

20 Mendall MA, Goggin PM, Molineaux N, Levy J, Toosy T Strachan D, et al. Childhood living conditions and Helicobacter pylori seropositivity in adult life. Lancet 1992 339: 896-7.

21 Peterson WL. Helicobacter pylori and peptic ulcer disease NEngl F Med 1991; 324: 1043-8.

22 Graham DY, Malaty HM, Evans DG, Evans DY, Klein PD Adam E. Epidemiology of Helicobacter pylori in an asymptomatic population in the United States. Gastroenterology 1991; 100: 1495-501.

23 Höök-Nikanne J. Effect of alcohol consumption on the risk of Helicobacter pylori infection. Digestion 1991; 50: 92-8.

\section{The EUROGAST Study Group}

Project Leader: Dr D Forman, Cancer Epidemiology Unit, Imperial Cancer Research Fund, Oxford, UK; Project Management Group: Dr M Coleman, Unit of Descriptive Epidemiology, International Agency for Research on Cancer, Lyon, France; Professor G De Backer, Department of Hygiene and Social Medicine, University Hospital, Ghent, Belgium; Professor I Elder, Department of Surgery, University of Keele, Stoke on J Elder, Department of Surgery, University of Keele, Stoke on Trent, UK; Dr H Møller, Danish Cancer Registry, Institute of Cancer Epidemiology, Danish Cancer Society, Copenhagen,
Denmark. EEC COMAC-EPIDEMIOLOGY Liaison Officer: Denmark. EEC COMAC-EPIDEMIOLOGY Liaison Officer:
Professor L Cayolla da Motta, National School of Public Health, Professor L Cayolla da Motta, National School of Public Health, Descriptive Epidemiology, International Agency for Research on Cancer, Lyon, France; Algeria: Dr L Abid, Registry of Digestive Tract Cancers, Bologhine Hospital, Algiers; Belgium: Professo $G$ de Backer, Department of Hygiene and Social Medicine University Hospital, Ghent; Denmark: Dr A Tiönneland, Danish Cancer Registry, Institute of Cancer Epidemiology, Danish Cancer Society, Copenhagen; Germany: Dr H Boeing, Mr T Haubrich, Professor J Wahrendorf, Institute of Epidemiology and Biometry, German Cancer Research Centre, Heidelberg; Greece: Professor O Manousos, Department of Gastroenterology, University General Hospital, Heraklion, Crete, Professor Aniversity General Hospital, Heraklion, Crete, Professor A Kafatos, School of Health Sciences, University of Crete, Heraklion, Crete; Iceland: Professor H Tulinius, Dr Ogmundsdottir, Icelandic Cancer Registry, Reykjavik; Italy: Study and Prevention of Cancer (CSPO), Florence; Japan: Dr A Fukao, Department of Public Health, Tohoku University, Sendai; Dr S Tsugane, Environmental Epidemiology Section, National Cancer Centre Research Institute, Tokyo; Dr Y Miyajima, Yokote Health Centre, Akita; Poland: Professor W Zatonski, Dr J Tycznski, Department of Cancer Control and Epidemiology, Institute of Oncology, Warsaw; Portugal: Professor J Calheiros, Epidemiology Unit, Institute of Biomedical Sciences Abel Salazar, University of Oporto, Oporto; Slovenia: Dr M Primic Zakelj, Epidemiology Unit, Institute of Oncology, Ljubljana; Dr M Potocnik, Blood Transfusion Centre of Ljubljana; Dr M Potocnik, Blood Transfusion Centre of Slovenia, Ljubljana; United Kingdom: Ms P Webb, ICRF Epidemiology Unit, Oxford, Dr T Knight, Ms A Wilson,
Department of Surgery, University of Keele, Stoke on Trent; Department of Surgery, University of Keele, Stoke on Trent; of Epidemiology, University of Minnesota, Minneapolis. Assay Laboratories: Helicobacter pylori antibodies: $\mathrm{Dr} D \mathrm{G}$ Newell, Department of Pathology, PHLS Centre for Applied Microbiology and Research, Porton Down, UK; Pepsinogen: Professo K J Hengels, Department of Gastroenterology, Heinrich Hein University, Dusseldorf, Germany; DNA adducts: Dr S Kyrtopoulos, Programme of Chemical Carcinogenesis, National Hellenic Research Foundation, Athens, Greece; DNA adducts: Dr C Wild, Unit of Mechanisms of Carcinogenesis, IARC, Lyon, France. Writing group for this paper: H Møller, P Webb, D Newell, D Forman, D Palli, K Hengels, J Elder, G De Backer, This study was partly supported financially as a Concerted Action by contract no: MR4-086-UK from the Directorate Biology, Directorate-General for Science, Research and DevelopBiology, Directorate-General for Science, Research and Develop-
ment Joint Research Centre, Commission of the European ment Joint 